\title{
Prevalence of Insomnia Among Patients with Bronchial Asthma
}

\author{
Abdullah AL-Harbi $\mathbb{D}^{1-3}$, Tammam Alanazi $\left.\mathbb{D}^{1}\right)^{\text {, Hazim Alghamdi }}{ }^{1}$, Meshal Alberreet', \\ Abdulaziz Alkewaibeen', Abdulrahman Alkhalifah', Aamir Omair $\mathbb{D}^{1,4}$, Mohammad Khan ${ }^{1-3}$, \\ Hamdan AL-Jahdali ${ }^{1-3}$ \\ 'College of Medicine, King Saud bin Abdulaziz University for Health Sciences, Riyadh, Saudi Arabia; ${ }^{2}$ Department of Medicine, Pulmonary Division, \\ King Abdulaziz Medical City, Ministry of National Guard-Health Affairs, Riyadh, Saudi Arabia; ${ }^{3}$ King Abdullah International Medical Research Center, \\ Riyadh, Saudi Arabia; ${ }^{4}$ Department of Medical education, College of Medicine, King Saud bin Abdulaziz University for Health Sciences, Riyadh, Saudi \\ Arabia
}

Correspondence: Abdullah AL-Harbi, Department of Medicine, Pulmonary Division, Ministry of National Guard-Health Affairs, P.O. Box 22490, MC 1443, Riyadh, II426, Saudi Arabia, Email harbia7@ngha.med.sa; draalharbi@yahoo.com

Background: Insomnia is commonly reported in patients with asthma. However, the prevalence of insomnia and its relationship to asthma control have not been established.

Objective: To determine the prevalence of insomnia in adults with asthma and to evaluate the association between insomnia and level of asthma control.

Methods: This is a cross-sectional study of 200 patients recruited from pulmonary clinics at a tertiary care center. Adults (age $\geq 16$ years) diagnosed with asthma by the primary treating physician were recruited over a 6-month period from December 2018 to May 2019. Asthma and insomnia severity were assessed using the Asthma Control Test and Insomnia Severity Index (ISI).

Results: The mean age of participants was $51 \pm 17$ years, and $67 \%$ were female. Insomnia (ISI score $\geq 10$ ) was present in $46.5 \%$ of the participants. The severity of insomnia was inversely related to the level of asthma control: moderate-to-severe insomnia was more frequent in patients with uncontrolled asthma (43\%) than in those with partially controlled asthma (25\%) or well-controlled asthma $(12 \%)(\mathrm{P}<0.05$ for all comparisons).

Conclusion: Insomnia is common among patients with asthma, especially those with suboptimal asthma control. Further investigations are required to more fully understand the complex relationship between asthma and insomnia.

Keywords: prevalence, asthma, insomnia, asthma control, Insomnia Severity Index

\section{Introduction}

Asthma is a common inflammatory respiratory disease characterized by intermittent symptoms of wheezing, dyspnea, cough, and chest tightness, combined with variable airflow obstruction, bronchial hyperresponsiveness, and chronic airway inflammation. ${ }^{1,2}$ The prevalence of asthma varies worldwide, ranging from approximately $5 \%$ to $20 \%$ in most countries. $^{3-7}$

Sleep disturbances and poor sleep quality are common among patients with asthma and are associated with poor quality of life. The causes of sleep disturbance are multifactorial and related to poor asthma control, as well as associated comorbidities, such as gastroesophageal reflux disease (GERD), obstructive sleep apnea, chronic rhinitis, and depression. $^{8-17}$ Insomnia is a frequent occurrence in patients with asthma and is characterized by difficulty with falling asleep, difficulty maintaining sleep, awakening too early, and daytime impairment resulting from the disturbed sleep. Insomnia symptoms have been reported in approximately one-third of patients with asthma, and the presence of these symptoms has been associated with worse of quality of life, more severe asthma symptoms, and increased health care utilization. $^{18}$ Nevertheless, limited data are available regarding the association between asthma severity and insomnia. ${ }^{19,20}$ 
The objectives of this study were to determine the prevalence of insomnia among a sample of adults with asthma in Saudi Arabia and to evaluate the relationship between insomnia and level of asthma control.

\section{Materials and Methods}

This cross-sectional study consisted of 200 adults with asthma recruited from pulmonary clinics at King Abdulaziz Medical City in Riyadh, Saudi Arabia, from December 2018 to May 2019. All adults (age $\geq 16$ years) with asthma evaluated during the study period $(\mathrm{n}=222)$ were invited to participate in the study, but 22 declined. The diagnosis of asthma was based on the primary treating physician's diagnosis plus documentation of reversible airflow obstruction on spirometry with a positive bronchodilator response and/or positive methacholine challenge test. ${ }^{1}$ Patients with the following conditions were excluded from the study: known sleep-disordered breathing, depression, other psychiatric illness, chronic obstructive pulmonary disease, interstitial lung disease, primary diagnosis of bronchiectasis, other chronic lung disease, neuromuscular disease, heart failure, liver disease, and renal failure. Patients with a smoking history of $>10$ pack-years were also excluded from the study.

The level of asthma control was assessed using the validated Arabic version of the Asthma Control Test (ACT). ${ }^{14-16}$ $\mathrm{ACT}$ is a validated instrument for assessing asthma control, with scores ranging from 5 to 25 . Based on ACT scores, the level of asthma control was classified into three groups: well-controlled, ACT $=20-25$; partially controlled, ACT $=16$ 19; and uncontrolled, ACT $=5-15 .^{17,18}$

Insomnia was assessed using the Arabic version of the Insomnia Severity Index (ISI). ${ }^{21}$ ISI is a well-validated instrument for evaluating insomnia symptoms. It consists of seven items, which assess falling asleep, difficulty maintaining sleep, waking up too early, dissatisfaction with sleep quality, daytime impairments resulting from the sleep disturbance, sleep problems noticed by others, and distress caused by sleep difficulties. Total ISI scores range from 0 to 28 , with scores $\geq 10$ indicating the presence of insomnia with an $86.1 \%$ sensitivity and $87.7 \%$ specificity. Based on final ISI scores, the severity of insomnia was classified into four groups: no insomnia, ISI $=0-7$; subthreshold insomnia, ISI $=8-14$; moderate insomnia, ISI $=15-21$; and severe insomnia, ISI $=22-28 .^{21,22}$

The study protocol was approved by the Institutional Review Board Committee at King Abdullah International Medical Research Center (SP18/368/R), and all participants provided written informed consent.

\section{Statistical Analysis}

All analyses were conducted using the Statistical Package for Social Sciences (SPSS v. 25.0; Armonk, NY, USA). Mean and standard deviation were used to summarize normally distributed data, whereas median and interquartile range were used for non-normal distributions. Categorical data were summarized as frequency and percentage. Demographic and clinical variables were compared between patients with and without insomnia using Student's $t$-test or chi-square test, as appropriate. Logistic regression analysis was used to identify risk factors associated with insomnia. $\mathrm{P}$ values $<0.05$ were considered statistically significant.

\section{Results}

Demographic and clinical characteristics of the study participants are detailed in Table 1. Insomnia (ISI $\geq 10$ ) was reported in 93 of 200 participants, for a prevalence rate of 46.5\%. The insomnia group was predominantly female (73\%), with a mean age of $54 \pm 16$ years. Demographics, asthma duration, and degree of airflow obstruction were not different between patients with and without insomnia. Sleep duration was shorter $(\mathrm{P}=0.01)$ and ACT scores were lower $(\mathrm{P}=$ 0.001) in the insomnia group than in the no insomnia groups.

The severity of insomnia differed across levels of asthma control. The prevalence of moderate or severe insomnia was higher in patients with uncontrolled asthma (43\%) than in patients with partially controlled asthma (25\%) or wellcontrolled asthma (12\%) ( $<0.05$ for all comparisons) (Table 2).

On multivariate regression analysis, the presence of insomnia (ISI $\geq 10$ ) was significantly associated with older age (odds ratio $[\mathrm{OR}]=1.02)$, obesity $(\mathrm{OR}=3.32)$, absence of GERD symptoms $(\mathrm{OR}=0.41)$, partially controlled asthma (OR $=8.45)$, and uncontrolled asthma $(\mathrm{OR}=3.59)(\mathrm{P}<0.05$ for all factors $)$ (Table 3$)$. 
Table I Baseline Characteristics in Patients with Different Levels of Asthma Control

\begin{tabular}{|c|c|c|c|c|}
\hline Characteristic & $\begin{array}{c}\text { All } \\
(n=200)\end{array}$ & $\begin{array}{c}\text { Insomnia } \\
(n=93)\end{array}$ & $\begin{array}{l}\text { No Insomnia } \\
\quad(n=107)\end{array}$ & $P$ value \\
\hline Age (years) & $51 \pm 17$ & $54 \pm 16$ & $47 \pm 17$ & 0.18 \\
\hline Female & $135(67)$ & $68(73)$ & $67(63)$ & 0.11 \\
\hline Married & $146(73)$ & $67(72)$ & $79(74)$ & 0.78 \\
\hline Educated $^{\ddagger}$ & $176(88)$ & $80(86)$ & $96(90)$ & 0.42 \\
\hline BMI $\left(\mathrm{kg} / \mathrm{m}^{2}\right)^{*}$ & $31(9.6)$ & $32(10)$ & $29(8.8)$ & 0.50 \\
\hline Ever smoked & $7(3)$ & $3(3)$ & $4(4)$ & 0.84 \\
\hline Coffee/tea intake & $3.0 \pm 3.0 / 2.0 \pm 1.8$ & $3.6 \pm 3.6 / 2.0 \pm 1.9$ & $2.6 \pm 2.7 / 1.8 \pm 1.7$ & $0.18 / 0.15$ \\
\hline Sleep duration, hours* & $6(2)$ & $5(3)$ & $6(2)$ & 0.01 \\
\hline \multicolumn{5}{|l|}{ Comorbid conditions } \\
\hline Allergic rhinitis & $96(48)$ & $43(46)$ & $53(50)$ & 0.64 \\
\hline GERD & $38(19)$ & $12(13)$ & $26(24)$ & 0.04 \\
\hline Diabetes mellitus & $71(35)$ & $35(38)$ & $36(34)$ & 0.56 \\
\hline Hypertension & $90(45)$ & $5 I(55)$ & $39(36)$ & 0.01 \\
\hline Asthma control test score & $17 \pm 4.9$ & $15 \pm 4.4$ & $19 \pm 4.5$ & 0.001 \\
\hline FEVI, \% predicted & $76 \pm 19.3$ & $83 \pm 23.2$ & $77 \pm 22.7$ & 0.32 \\
\hline FVC, \% predicted & $82 \pm 22.6$ & $83 \pm 22.7$ & $82 \pm 20.7$ & 0.34 \\
\hline FEVI/FVC, \% predicted & $77 \pm 15.7$ & $79 \pm 12.9$ & $77 \pm 15.6$ & 0.45 \\
\hline ISI score & $10 \pm 7.2$ & $16 \pm 4.5$ & $4 \pm 2.9$ & 0.001 \\
\hline
\end{tabular}

Notes: Data were expressed as mean \pm standard deviation or as a number (percentage) unless otherwise specified. *Median (interquartile range). ${ }^{\ddagger}$ Educated: achieved more than primary school.

Abbreviations: BMI, body mass index; GERD, gastroesophageal reflux disease; ISI, Insomnia Severity Index.

Table 2 Insomnia Severity Index Comparisons According to Level of Asthma Control

\begin{tabular}{|c|c|c|c|c|}
\hline & \multicolumn{3}{|c|}{ Asthma Control } & \multirow[b]{2}{*}{$P$ value } \\
\hline & $\begin{array}{l}\text { Well-Controlled } \\
\qquad(n=67)\end{array}$ & $\begin{array}{l}\text { Partially Controlled } \\
\qquad(n=55)\end{array}$ & $\begin{array}{l}\text { Uncontrolled } \\
\qquad(n=78)\end{array}$ & \\
\hline Total ISI score, median (IQR) & $2(6)$ & $9(10)$ & $12(9)$ & $<0.001$ \\
\hline Insomnia, ISI $\geq 10$ & $13(19 \%)$ & $27(49 \%)$ & $53(68 \%)$ & $<0.001$ \\
\hline \multicolumn{5}{|l|}{ Insomnia severity } \\
\hline No insomnia (ISI = 0-7) & $52(78 \%)$ & $23(42 \%)$ & $15(19 \%)$ & \multirow[t]{4}{*}{$<0.001$} \\
\hline Sub-threshold insomnia $(I S I=8-14)$ & $7(10 \%)$ & $18(33 \%)$ & $30(38 \%)$ & \\
\hline Moderate insomnia (ISI = |5-2|) & $7(10 \%)$ & $10(18 \%)$ & $24(31 \%)$ & \\
\hline Severe insomnia $(I S I=22-28)$ & I (2\%) & $4(7 \%)$ & $9(12 \%)$ & \\
\hline
\end{tabular}

Abbreviations: IQR, interquartile range; ISI, Insomnia Severity Index. 
Table 3 Factors Associated with the Presence of Insomnia

\begin{tabular}{|l|c|c|c|}
\hline & Odds Ratio & $95 \%$ Cl & P value \\
\hline Age (years) & 1.02 & $1.00-1.05$ & 0.04 \\
\hline Female & 1.55 & $0.72-3.36$ & 0.26 \\
\hline Married & 0.70 & $0.33-1.50$ & 0.37 \\
\hline Educated ${ }^{\ddagger}$ & 1.05 & $0.37-2.97$ & 0.93 \\
\hline Ever smoked & 1.61 & $0.27-9.55$ & 0.60 \\
\hline Coffee/tea intake & 0.57 & $0.17-1.95$ & 0.37 \\
\hline BMI $\geq 30$ kg/m & 3.32 & $1.15-9.62$ & 0.03 \\
\hline Allergic rhinitis & 1.01 & $0.52-1.97$ & 0.97 \\
\hline GERD & 0.41 & $0.17-0.96$ & 0.04 \\
\hline Partially controlled asthma & 8.45 & $3.68-19.39$ & 0.001 \\
\hline Uncontrolled asthma & 3.59 & $1.49-8.64$ & 0.004 \\
\hline
\end{tabular}

Note: ${ }^{\ddagger}$ Educated: achieved more than primary school.

Abbreviations: $\mathrm{BMI}$, body mass index; $\mathrm{Cl}$, confidence interval; GERD, gastroesophageal reflux disease.

\section{Discussion}

In this study, we determined the prevalence of insomnia among a sample of adults with asthma seen in specialized pulmonary clinics at a tertiary care center in Saudi Arabia and examined the association between insomnia and level of asthma control. We found a high prevalence of insomnia, with almost one-half of all patients reporting insomnia symptoms (ISI $\geq 10$ ). Moreover, asthma control was inversely related to insomnia; insomnia was more common in patients with partially controlled or uncontrolled asthma than in those with well-controlled asthma.

The high prevalence of insomnia in our sample of asthmatic patients (46.5\%) was consistent with the prevalence rates of $22 \%$ to $47 \%$ reported in the literature. ${ }^{19,20,23-28}$ In their study of 714 participants in the Severe Asthma Research Program III, Luyster et $\mathrm{al}^{19}$ found an insomnia prevalence rate of $37 \%$. Among 470 asthmatic patients from Nordic countries who participated in the European Community Respiratory Health Survey II, Sundberg et $\mathrm{al}^{20}$ observed an insomnia prevalence rate of $20 \%$ in men and $45 \%$ in women.

Our results also revealed that the prevalence and severity of insomnia differed across different levels of asthma control. Insomnia was reported by $68 \%$ of the patients with uncontrolled asthma, $49 \%$ of the patients with partially controlled asthma, and only $19 \%$ of those with well-controlled asthma. Moreover, moderate or severe insomnia was more frequent among patients with uncontrolled or partially controlled asthma than in patients with well-controlled asthma. In the abovementioned study by Luyster et al, ${ }^{19}$ the presence of not well-controlled asthma (ACT score $\leq 19$ ) was associated with a 2.4-times increased risk of insomnia. Furthermore, not well-controlled asthma was reported by $78 \%$ of the patients with insomnia and $53 \%$ of those without insomnia. ${ }^{19}$ Sundbom et al $^{20}$ also reported a higher prevalence of insomnia in patients with uncontrolled asthma (32\%) than in those with partially controlled asthma (20\%) or controlled asthma (20\%). A bidirectional association is noted between asthma and chronic insomnia. A prospective study conducted by Brumpton et $\mathrm{al}^{31}$ which include 17927 participants who are free from asthma at baseline; 686 were diagnosed with asthma during the 11 -year follow-up. The study showed three times increase in the risk of incident asthma in patients with chronic insomnia. ${ }^{31}$

The association between insomnia and absence of GERD was unexpected finding and a strong possibility exists that the association is a chance finding due to small number of patients with GERD $(n=38)$. Previous studies showed high prevalence of GERD in patients with insomnia. ${ }^{29,30}$

This study has some limitations that warrant consideration. First, it is a cross-sectional study, which precludes us from making causal inferences regarding the association between insomnia and asthma control. Second, the study included a relatively low number of participants, and these participants were recruited from subspecialty clinics at a tertiary center 
and were predominantly women. Thus, there is a possibility of selection bias, and our findings may not be generalizable to other settings with different resources. Third, the lack of a matched control group without asthma prevented us from comparing the prevalence of insomnia between adults with and without asthma. Fourth, theit is a cross-sectional study conducted over a short period. Both asthma and insomnia vary in their severities throughout the seasons, which influences asthma control and insomnia. It also needs to be taken into consideration as it can affect the prevalence of insomnia and the severity of asthma. Lastly, objectives measurements of sleep disturbance, such as sleep studies for OSA and sleep diaries, were not done.

\section{Conclusions}

Insomnia is common among patients with asthma, especially those with suboptimal asthma control. Further studies are required to better understand the complex relationships between asthma and insomnia.

\section{Data Sharing Statement}

The datasets used and/or analysed during the current study are available from the corresponding author on reasonable request.

\section{Ethics Approval and Consent to Participate}

The study was approved by the institutional review board of King Abdullah International Medical Research Center (KAIMRC) in Riyadh, Saudi Arabia. All procedures performed in studies involving human participants were in accordance with the ethical standards of the institutional and/or national research committee and with the 1964 Helsinki declaration and its later amendments. Written informed consent was obtained from all participants.

\section{Author Contributions}

All authors made a significant contribution to the work reported, whether that is in the conception, study design, execution, acquisition of data, analysis and interpretation, or in all these areas; took part in drafting, revising or critically reviewing the article; gave final approval of the version to be published; have agreed on the journal to which the article has been submitted; and agree to be accountable for all aspects of the work.

\section{Funding}

This study received no funding.

\section{Disclosure}

The authors declare that they have no competing interests.

\section{References}

1. National asthma education and prevention program: expert panel report III: guidelines for the diagnosis and management of asthma. Bethesda, MD: National Heart, Lung, and Blood Institute; 2007. (NIH publication no. 08-4051). Available from: www.nhlbi.nih.gov/guidelines/asthma/asthgdln. htm. Accessed August 03, 2021.

2. Global Initiative for Asthma. Pocket Guide for asthma management and prevention for adults and children older than 5 Years; 2018.

3. Sears MR. Trends in the prevalence of asthma. Chest. 2014;145(2):219-225. doi:10.1378/chest.13-2059

4. Baïz N, Annesi-Maesano I. Is the asthma epidemic still ascending? Clin Chest Med. 2012;33(3):419-429. doi:10.1016/j.ccm.2012.06.001

5. Centers for Disease Control. Most recent national asthma data. 2019; Available from: https://www.cdc.gov/asthma/most_recent_national_asthma_ data.htm. Accessed January 18, 2022.

6. Bucca C, Romano C, de Marco R, et al. Variations in the prevalence of respiratory symptoms, self-reported asthma attacks, and use of asthma medication in the European Community Respiratory Health Survey (ECRHS). Eur Respir J. 1996;9(4):687-695. doi:10.1183/ 09031936.96.09040687

7. Mohamed Hussain S, Ayesha Farhana S, Mohammed Alnasser S. Time trends and regional variation in prevalence of asthma and associated factors in Saudi Arabia: a systematic review and meta-analysis. Biomed Res Int. 2018;2018:8102527. doi:10.1155/2018/8102527

8. Sherbini N, Al-Harbi A, Khan M, Al-Jahdali H. Asthma and sleep. In: Pandi-Perumal SR, editor. Synopsis of Sleep Medicine [Book on the Internet]. 1st ed. Oakville, ON: Apple Academic Press; 2016:363-377.

9. Braido F, Baiardini I, Ghiglione V, et al. Sleep disturbances and asthma control: a real life study. Asian Pac J Allergy Immunol. 2008;27:27-33. 
10. Janson C, De Backer W, Gislason T, et al. Increased prevalence of sleep disturbances and daytime sleepiness in subjects with bronchial asthma: a population study of young adults in three European countries. Eur Respir J. 1996;9(10):2132-2138. doi:10.1183/09031936.96.09102132

11. Krouse HJ, Yarandi H, McIntosh J, Cowen C, Selim V. Assessing sleep quality and daytime wakefulness in asthma using wrist actigraphy. J Asthma. 2008;45:389-395. doi:10.1080/02770900801971800

12. Mastronarde JG, Wise RA, Shade DM, Olopade CO, Scharf SM. Sleep quality in asthma: results of a large prospective clinical trial. $J$ Asthma. 2008;45:183-189. doi:10.1080/02770900801890224

13. Alanazi TM, Alghamdi HS, Alberreet MS, et al. The prevalence of sleep disturbance among asthmatic patients in a tertiary care center. Sci Rep. 2021;11(1):1-7. doi:10.1038/s41598-020-79697-x

14. Lababidi H, Hijaoui A, Zarzour M. Validation of the Arabic version of the asthma control test. Ann Thorac Med. 2008;3(2):44-47. doi:10.4103/ $1817-1737.39635$

15. Al-Zahrani JM, Ahmad A, Al-Harbi A, et al. Factors associated with poor asthma control in the outpatient clinic setting. Ann Thorac Med. 2015; 10 (2):100-104. doi:10.4103/1817-1737.152450

16. Al-Jahdali HH, Al-Hajjaj MS, Alanezi MO, Zeitoni MO, Al-Tasan TH. Asthma control assessment using asthma control test among patients attending 5 tertiary care hospitals in Saudi Arabia. Saudi Med J. 2008;29(5):714-717.

17. Nathan RA, Sorkness CA, Kosinski M, et al. Development of the asthma control test: a survey for assessing asthma control. J Allergy Clin Immunol. 2004;113(1):59-65. doi:10.1016/j.jaci.2003.09.008

18. Schatz M, Sorkness CA, Li JT, et al. Asthma Control Test: reliability, validity, and responsiveness in patients not previously followed by asthma specialists. J Allergy Clin Immunol. 2006;117(3):549-556. doi:10.1016/j.jaci.2006.01.011

19. Luyster FS, Strollo PJ Jr, Holguin F, et al. Association between insomnia and asthma burden in the Severe Asthma Research Program (SARP) III. Chest. 2016;150(6):1242-1250. doi:10.1016/j.chest.2016.09.020

20. Sundbom F, Malinovschi A, Lindberg E, Almqvist C, Janson C. Insomnia symptoms and asthma control-Interrelations and importance of comorbidities. Clin Exp Allergy. 2020;50(2):170-177. doi:10.1111/cea.13517

21. Suleiman KH, Yates BC. Translating the insomnia severity index into Arabic. J Nurs Scholarsh. 2011;43(1):49-53. doi:10.1111/j.15475069.2010.01374.x

22. Morin CM. Insomnia, Psychological Assessment and Management. New York: Guilford Press; 1993.

23. Alt JA, Ramakrishnan VR, Platt MP, et al. Sleep quality outcomes after medical and surgical management of chronic rhinosinusitis. Int Forum Allergy Rhinol. 2017;7:113-118. doi:10.1002/alr.21860

24. Davies SE, Bishopp A, Wharton S, et al. The association between asthma and obstructive sleep apnea (OSA): a systematic review. $J$ Asthma. 2018;56:1-12

25. Tsuno N, Besset A, Ritchie K. Sleep and depression. J Clin Psychiatry. 2005;66(10):1254-1269. doi:10.4088/JCP.v66n1008

26. Sundbom F, Malinovschi A, Lindberg E, Alving K, Janson C. Effects of poor asthma control, insomnia, anxiety and depression on quality of life in young asthmatics. J Asthma. 2016;53(4):398-403. doi:10.3109/02770903.2015.1126846

27. Sundbom F, Lindberg E, Bjerg A, et al. Asthma symptoms and nasal congestion as independent risk factors for insomnia in a general population: results from the GA(2) LEN survey. Allergy. 2013;68(2):213-219. doi:10.1111/all.12079

28. Sundberg R, Torén K, Franklin KA, et al. Asthma in men and women: treatment adherence, anxiety, and quality of sleep. Respir Med. 2010;104 (3):337-344. doi:10.1016/j.rmed.2009.10.017

29. Mody R, Bolge SC, Kannan H, Fass R. Effects of gastroesophageal reflux disease on sleep and outcomes. Clin Gastroenterol Hepatol. 2009;7 (9):953-959. doi:10.1016/j.cgh.2009.04.005

30. Jansson C, Nordenstedt H, Wallander MA, et al. A population-based study showing an association between gastroesophageal reflux disease and sleep problems. Clin Gastroenterol Hepatol. 2009;7(9):960-965. doi:10.1016/j.cgh.2009.03.007

31. Brumpton B, Mai XM, Langhammer A, Laugsand LE, Janszky I, Strand LB. Prospective study of insomnia and incident asthma in adults: the HUNT study. Eur Respir J. 2017;49(2):1601327. doi:10.1183/13993003.01327-2016

Journal of Asthma and Allergy

\section{Publish your work in this journal}

The Journal of Asthma and Allergy is an international, peer-reviewed open-access journal publishing original research, reports, editorials and commentaries on the following topics: Asthma; Pulmonary physiology; Asthma related clinical health; Clinical immunology and the immunological basis of disease; Pharmacological interventions and new therapies. The manuscript management system is completely online and includes a very quick and fair peer-review system, which is all easy to use. Visit http://www.dovepress.com/testimonials.php to read real quotes from published authors.

Submit your manuscript here: https://www.dovepress.com/journal-of-asthma-and-allergy-journal 